\title{
Perceptions of Power and Democracy: Analytical and Methodological Dilemmas of the Construction of Images
}

\author{
Niels Nørgaard Kristensen
}

\begin{abstract}
How is political identity and power understood in post modern society? This paper uses a single qualitative interview with a truck driver to investigate the elements that impact the formation of political identity. The paper suggests a qualitative bottom up approach as a method and as a way of inquiry into understandings of identity and perceptions and discusses the interview against advantages and dilemmas of the design.
\end{abstract}

Key words: power, political identity, bottom up approach, constructivism.

Please cite this article as: Kristensen, N. N. (2010). Perceptions of power and democracy: Analytical and methodological dilemmas of the construction of images. Qualitative Studies, 1(1): 18-32.

\section{Introduction}

This paper is investigating the understanding of political perceptions by analysing an interview with a truck driver, selected as part of a larger case study. The purpose is to unfold $a$ hermeneutics of the political subject, which means uncovering opinions, understandings, perceptions and practices in relation to democracy, politics and political power - which de facto is "non-observable." It takes a qualitative methodology and constructivist epistemological position under scrutiny and offers a discussion of the advantages and drawbacks of an approach, which could be labelled a constructivist bottom up approach. Subsequently, it seeks to add to the political sociology of post modernity and the knowledge of political identity. The paper addresses the following questions: How do people conceptualize and experience power in a modern democracy - e.g. do people feel that they have a say? How is power and politics dealt with in everyday life? The paper looks into the analysis of the data from one respondent in the larger case study.

\begin{abstract}
Aim of the study and scientific method
In a study under the auspices of The Danish Democracy and Power Study - "Billeder af magten" (Kristensen, 2003) - on which this paper draws, the focus is specifically on how the members of contemporary Danish society experience power and their own role in democracy. The study implies a general inquiry of features of the socio-cultural world - dispositions, practices, processes that constitute pre-conditions for people's actual participation in politics and civil society. In short, these preconditions involve cultural attributes prevalent among citizens that can, in various ways, facilitate democratic life. This notion of civic culture is anchored in everyday life and its horizons, and can thus be seen as an important region of the Habermarsian life world with its negotiation of norms and values (Habermas, 1996; Dahlgren, 2003). I shall not go over the study here, but it will serve as a basic surrounding for the discussion of central methodological issues.
\end{abstract}

Culture consists of patterns of practices and meaning, and they provide taken for granted orientations - factual and normative - as well as other resources for collective life. They are internalised intersubjectively: they exist "in our heads", guiding and informing action, speech and understanding (Dahlgren, 2001). Some of the problems involved when working with 
phenomena such as meaning, opinion, attitudes, etc. - is that you get the information "second hand" - you just really cannot plug out an idea or understanding of peoples heads, and you have no direct access to the data (Lewis, 1991). You simply have to rely on your methodological framework. The methodological approach used in the study involves "intruding" into the respondents' world - subsequently trying to condense, reconstruct and interpret meaning and belief systems - in relation to democracy, societal power and political action. The analysis must be able to uncover the tacit knowledge involved in relation to political identity (not quite unlike Althusser's concept of "symptomalistic reading"; Althusser, 1969). This notion thematises the connection between actual conditions and the subjective experience of the same, cf. Marx's distinction between objective and subjective class - class an "sich"l"für sich" (Marx \& Engels, 1992 [1848]). This points to - at least - three seminal and basic methodological problems:

1. How do we know what the actual conditions - or the "objective" positions (of identity) - are?

2. How do we know that we are locating the actual subjective understanding of the respondent?

3. How do we construct a coherent power image from the data?

At least since Phillip Converse's 1964 seminal article - "The Nature of Belief Systems in Mass Publics" - political scientists have strived for ways of unfolding citizens' political beliefs (and almost exclusively doing so from a positivist methodology). This approach suggests, however, that most individuals' political beliefs are characterized by high levels of ambivalence - and, following, that people should not be provided fixed-choice questions, but should rather be given a chance to talk. Hence, a qualitative methodology is preferred. People do not make simple statements - they shade, modulate, deny, retract, or just grind to a halt in frustration. Such manifestations of uncertainty much be seen as just as meaningful and interesting, as the definitive statements of a belief system (Hochschild, 1981).

Foucault tells us, that power is everywhere (Foucault, 1982). His notion of a net of force relations represents ontology: a specification of basic aspects of sociality (Schatzki, 2006). At the level of epistemology the methodological approach in use is constructivist as well as bottom uporiented. This means, firstly, that it sees reality as being socially constructed. It thereby rejects "essentialist" epistemological understandings of political life, its actors and institutions. The aim is not to uncover life worlds in a naturalistic manner, but rather to examine the understandings and the production of meaning through which the social world is constituted. Instead, an anti-essential perspective is suggested - giving priority to action and identity construction as the foundation of empirical inquiry. In a constructivist ontology reality is not simply "out there"; instead, it is always under the influence of the "lenses" through which we view it. Secondly, the approach is bottom up-oriented, challenging top-down approaches to identity operating on the precondition that there exists a tight correspondence between structural position and identity. Instead, the approach is founded in a research design using case studies and a qualitative, inductive approach (Sørensen 1998). In this respect it draws on a large body of literature (e.g. Ragin \& Becker, 1992; Yin, 1994; Flyvbjerg, 2001; Prasad, 2005).

Also, it is grounded in a notion of everyday life, citizenship and political identity - by establishing a broad conception of politics - where politics is seen as a major force penetrating the life world realms. What I aim for here, is a position that is neither macro or micro - or neither objectivism or subjectivism - but takes into consideration the empirically guided focus on context and everyday life. By "context", I mean the specific surroundings to a given case or biography, thereby indicating - not a micro oriented focus (with its unacceptable voluntarism) and not a macro oriented focus (with its unacceptable determinism), but exactly a mix between 
these positions. Chantal Mouffe argues for conceiving of the social agent not as a unitary subject but as the articulation of an ensemble of subject positions, constructed within specific discourses and always precariously and temporarily sutured at the intersection of those subject positions. She advocates developing a non-essentialist conception of the subject and regarding identity as identification rather than essential properties of the subject (Mouffe, 1993).

29 interview persons were selected for the case study on the basis of a number of different ordinary characteristics like gender, age, occupation, geography, etc., but also on the basis of their capacity to represent certain types or stereotypes, e.g. the traditional worker, the farmer, the unemployed, the pensioner, the political activist, the official, the ICT-innovator, the selfemployed entrepreneur, the student, the manager, the professional. The respondents were interviewed individually - with the interviews lasting from 1-3 hours. The purpose was not to select a representative stratification, but to seek variation. A wide range of issues such as political identity, societal power (or lack of power), political awareness, level of political knowledge, political liabilities, work situation, sources of information and attitudes towards the media were addressed during the interviews. A semi-structured interview guide was used during the interviews, but only for guidance, as I took on a "narrative" approach (Van Maanen, 1988); largely letting people themselves tell their stories. The interviews were transcribed and given a preliminary analysis. 11 of these 29 interviews - the ones I found most informative were transformed into what I call "political biographies" - and were treated to deep analyses in a manner which is unfolded in this chapter. Then - following - the analyses or main findings were sent to the respondents for comments, corrections and validation. The truck driver, who will be presented in this article, was initially "picked" for the study as a representative of a typical Danish tabloid newspaper reader. The research questions in the study were:

- How are power relations experienced and which forms of power are pointed out?

- From where is power seen? What are the originates of power perceptions? A distinction is made here between foundations in local and distant power relations. On a more fundamental level, how is the understanding of power basically constructed (e.g. dichotomically/hierarchically - pluralistic/egalitarian)?

- How is one's own role in democracy experienced?

Research question 1) treats power perceptions as the dependent variable, where as in 2) it shifts into being the independent variable; 3 ) thematises the questions of political engagement and empowerment.

In the following I will lay out the fundamentals for my strategy of analysis. We are all carrying around various specific conceptions of society - regarding equality and diversity, position and status, degrees of separation from power, etc. My approach to the interpretation of the data can be illustrated through this real-life example: In the period, when I was doing my interviewing, I incidentally had a brief experience involving such perceptions. One day I was doing my grocery shopping on a lovely day of spring. Beside the parking lot outside "Netto" (a Danish grocery store renowned for its low prices), a ca. 60-year-old woman is standing and enjoying the sun. She obviously has good time on her hands. We smile to one another as I get out of my car. At the very same moment, a fellow drives by in a red, open convertible sports car. He parks the car a little ways away. 
"Hey - isn't that an MG?" She enquired.

"I think so," I replied, "but I'm no expert." My familiarity with cars, sports cars in particular, is hardly impressive.

"Hmm. There's something that just doesn't fit," she continued.

"Pardon me?"

"Yeah - "Netto" and an MG!"

This brief anecdote serves to demonstrate how we have very precise expectations regarding specific relationships when we are constructing understandings and images of how things fit together. What is fascinating is that even though we live in the same society and share the same "objective" reality, we interpret it in entirely different ways. We construct various matrices through which we perceive the world around us, and the task for the analyst is to uncover or decompose the matrices in order to reveal how such understandings of society and power are formed. For example, what is the nature of the relationship between one's own experiences and the manner in which one experiences structures of societal life? We all have stereotypical senses of the order of things in this world, and these can be particularly informative, both in terms of the manifest understandings of power and the more latent and shrouded perceptions and means of structuring reality. Consequently, I approach the analyses by looking for basic understandings and (also stereotypical) perceptions like in the real life example, simply because such understandings are highly informative and offer insights, which might not be gained via a "standard" research design. These points and possible origins of power perceptions are further elaborated from various theoretical perspectives below.

\section{Mediated vs. practice-based identities and conceptions of power}

Identities and everyday cultures incarnate central features and characteristics of actors. Not only are they indicative of values, they also express an individual dimension of acknowledgement. The central analytical question in this section is: From where do people primarily pick up or construct perceptions of power?

The literature on power is voluminous, and the body of works on identity is growing (Calhoun, 1995; Delanty, 2000; Jenkins, 2004; Smith, 2004). Neither can be presented in a just way here. Historically, the British Cultural Studies tradition has been a prominent provider of related work. A central analytical point of departure for this tradition was the connection between the objective class situation and consciousness, i.e. the subjective understanding of this situation (Bulmer, 1975). Classic studies of workers' images of power (Lockwood, 1966; Bulmer, 1975) indicate that it is the power situation in relation to ones immediate surroundings and employment situation that structures perceptions of wider societal power relations. Society is understood here as constituting an aggregated and magnified body of the hierarchy of working life, i.e. as the enterprise "writ large", with the same authoritarian relations and the same level of disempowerment. In terms of a distinction between near/distant power relations, this tradition exclusively picks up on the former. The relevance of this assumption is, however, increasingly questioned today, as factors including the relationship between the media, the public, cultural pluralisation, globalisation etc. are entirely absent in this tradition. Modern society is marked by a pronounced spatial, temporal and institutional differentiation, and it is necessary to seek influences in the more "distant" relations, including globalisation and processes in the media. Media presumably plays a central role concerning the formation of political attitudes (Beck, 1992). The power of the media is, therefore, increasingly seen as a fundamental aspect of modern society, and citizens' experiences of democratic processes are increasingly linked to understandings of mediated political communication - both in relation to political processes of 
regulation and individuals' understandings of society and its problems (Bennett \& Entman, 2001). We live today in a mass media-saturated environment (Gibbins \& Reimer, 1999). We encounter a "mediated reality" where a vast majority of political activity is conducted with the media in mind, and the public receive the vast majority of their information from media reporting (Bennet \& Entman, 2001; Lilleker, 2006). The mass media remains the key mode for reaching a mass audience thus serving as a factor, which conceivably facilitates or hands over certain political understandings, images and perceptions. In this way, media cease being "media" in the original sense of the word - that is as the messenger of information and communication from a sender to a receiver. Instead, modern media transform into a kind of means of perception - which independently constructs, produces and arranges the "reality" which is publicly deliberated and contemplated: Reality is medialised. Some, on the other hand, pay attention to more delicate changes in patterns of political orientation and participation and the growth of "lifestyle politics" (Bennett, 1998), which is characterized by an individualized, rather than a collective, engagement, and increased attention to single-issue-policies rather than ideology and overarching political issues. In a Scandinavian setting Dahlgren and others have argued for serious changes in the political culture, hereby stressing changes in the functioning of democracy (Dahlgren, 2003).

It is a well-established assumption in sociology that if people are incapable of controlling or coping with the world around them, they will simply reduce it to the dimensions of their immediate surroundings (Castells, 1983). Hermeneutics therefore often examine the down-toearth experiences as a part of the filter and "tool box" used to process and interpret the more distant phenomena including the political system. Late modernity, for instance, forces the individual to constantly make decisions (i.e. to act reflexively). This gives rise to a need for ontological certainty and practically grounded knowledge pertaining to everyday life, which Anthony Giddens (1991) refers to as the practical consciousness. Practical consciousness is linked to the rules, routines and strategies that serve as the basis for the constitution of everyday social life in relation to time and space. The term can be drawn upon in relation to abstract systems, e.g. expert systems, which increasingly have an effect on our everyday life.

The practical consciousness - or "practical understanding" - affects the field of identity formation and the field of perceptions of power, and it points to a notion of immediacy, when accounting for sources of power perceptions. In the way it is used in this study, however, this does not mean to constitute some kind of immediate, life form based formation of identity i.e. a kind of essential identity or kernel of identity. The "practical understanding" is in this sense also a kind of constructed or mediated understanding. Modern identity formation is - in other words - seen as a process of construction, but it is a process of construction based on experience and with limitations and inertia belonging to it, not an arbitrary one with a free individual choice. Still, the formation of political attitudes and awareness can hardly be narrowly understood as an extension of the work sphere, as in the Lockwood-tradition, where almost all aspects of the social are derived from working life. It is hardly possible in studies of contemporary society to assume beforehand that working life fundamentally lays out the structure for our entire life form. There are a number of forms of structure found in modern society that must be assumed to be common for all, regardless of occupation.

An example of a current identity construction will be presented in the following section via the analysis of long-distance truck driver, Joergen. It gives an insight into specific world views and more fundamental ways of structuring understandings, which are building on an everyday life context in the sense-making of society and political life. This respondent notably uses his 
practical consciousness for construction of images of power.

\section{Analysis: Joergen, the truck driver}

Joergen is a 43 years old truck driver living in the Danish town Viborg. Joergen is divorced, and today he lives alone in an apartment. After finishing school, he became a working boy before joining the military. Following his military training, he started working as a truck driver for a demolition company. He subsequently began working as a haulage contractor together with his brother, the two of them establishing a moving company. The brother later quit, but Joergen continued on his own with export hauling for fifteen years, where he primarily drove between Denmark and Southern Germany. He is now driving a forklift in a large factory. Long-distance trucking represents a lifestyle - not just a job - Joergen explains. The thing about the job that he liked was the dream of being a "free bird" on the road. He usually drove with furniture to Germany. When Joergen was away from home, he lived in his truck, which was furnished with a bunk, coffee machine, refrigerator and stove - "it had everything." He did not miss a thing, he insists: there was electricity, television and a video. "I have always been my own person - kind of different", he says: "Nobody is going to tell me what to do." Joergen has a deeply felt need for autonomy and the profession as a trucker serves this purpose. Therefore, he tells, he got a truck and started his own company.

Joergen is a fine example of someone whose identity and understandings of politics, democracy and power to a large extent are structured by the life world and the "immediate." He shows this in his comments of the relationship between politicians and laymen and the question about political authority and public regulation, e.g. the dichotomy between political systems "experts" and life world "experts", which he thematises on the basis of the sociological phenomena of traffic:

Joergen: There's something that drives me crazy - I mean, the politicians have been told by an expert that if speeds are increased by ten kilometres per hour, then " $x$ "-number of people will die. That's just not true, right? I mean - why do those people die? Sure, if something goes wrong for them, then the speed contributes to making the situation worse. If we all drive $0 \mathrm{~km} /$ hour, then nobody will die. That's a good beginning, but people will ultimately go crazy. That just can't be right when we are on a four-lane highway, which is fully illuminated, and everything is OK and our cars are equipped with the latest ABS things and whatever else you can get. Then you are sitting there and doing $80 \mathrm{~km} / \mathrm{h}$, because politicians have figured out that it is the most defendable. That is what we are able to manage. And down on the other side of the line (Germany; my addition NNK), they are driving $180 \mathrm{~km} / \mathrm{h}$ instead; because they say that they can handle it.

Joergen appears far from an apathetic or alienated political identity. He has been a member of a political party for all of his adult life - notably various rightwing and liberal parties - linking entrepreneurship and petty-bourgeoisness to membership of political parties. Obviously, Joergen does not simply roll over and subject himself to regulation and management from above. "I decide how fast I am going to drive on the highway. For the politicians are incompetent", he says. Perhaps they are listening to expert advice, but Joergen will not acknowledge their expertise. As such, they have no sense of what is actually going on - no idea of the reality on the road, he thinks. As to politicians getting involved via legislation, Joergen seems incited by the dichotomy between those in control and those being controlled, i.e. the vertical dimension between authorities and citizens. His understandings are to a large extension based on the experiences from the system of traffic. As an individual motorist, in traffic we are operating in 
the field of tension between collective rules and individual freedom - between community and autonomy. For Joergen, the motor vehicle is a symbol of freedom and an image of autonomy and it represents an open, free space, where one can be oneself. Politics and state (e.g. traffic regulation) are here equated with paternalism and judicial know-all'ism, as unfolded by politicians and technical experts. The automobile thus becomes a metaphor for freedom itself: The real world and the system are locked out, and one is free to "be oneself." In the car, it is legitimate to think about oneself, demand ones rights or pursue personal interpretations of what constitutes "proper" driving. "I just pay the fine, if I get caught", he states. In my readings of Joergen's everyday cognitive understandings, traffic consequently represents the key word when one is seeking to gain access to Joergen's wider perceptions of society and power. Admitted, I do make a major conceptual leap between micro and macro levels, when I am linking life world perceptions to notions of identity and power. But in the interview situation, I did not invoke these metaphors. The respondent himself brought these issues up.

Joergen: The other day - we were driving to work. We have a four-lane road down towards Århus, so I come driving on some guy's tail, and he pulls out in the passing lane. I know that there are ruts in the slow lane and it is better to drive in the passing lane, but when he can see me coming and that I am going to pass him, and then he is obligated to remain in the first lane, regardless of the road conditions. But then he can see me, so he just starts driving faster, because then he is at least able to accelerate away from me. But then I got mad at him, and I said to myself, "He isn't going to get away from me", because my car is a little stronger, apparently, so I pull up on his tail, but he stays out there in the passing lane. So, then I thought - hey, I don't feel like arguing about this with him, so I just passed him on the inside. And that was that.

It appears as though Joergen displays a certain degree of high-handedness behind the wheel; the traffic concerns Joergen's own, specific empowerment strategy, but in a more figurative sense, it also serves as a metaphor for societal interaction in general, and power in particular. It is thus decisive for Joergen's understanding of society and a means by which he constructs understandings of the world around him. This image of traffic is generally also suitable for describing more fundamental mechanisms in society and democracy. Joergen reveals how the notion of democracy and the paroles of "liberty, equality and fraternity" are exposed in this magnified reading of the system of traffic, which becomes a true model of democracy. We saw above, how the issue of liberty is amplified in the stressing of individual autonomy. Also, the notion of equality is easily found. On the one hand, motor vehicles represent a source of power. At the same time, they also represent a symbol of "absolute" democracy and complete equality of power. In the traffic, we are all equal. The CEO does not have rights that ordinary people do not. Status and income make no difference. Or as Joergen points out:

Joergen: Handicapped people also become equals when they come whizzing on by. They have specialized cars. And then when they have to get out of their car, they cannot do a thing. But as long as they are sitting in their car, they are on equal terms with everybody else behind the wheel of a car. So that is probably where we are most equal as citizens. We are born equal, and we are equal when we are driving our cars.

One can hardly articulate it much clearer. According to this metaphor, traffic also becomes an image of empowerment: everyone, Joergen says, even the handicapped, can hold their own. At the same time, it becomes an image of an important democratic principle concerning equality and justice ("fraternity"): in the traffic, we are equal in the formal sense, just as we are also equal before the law in society in general. On the other hand, we are not really equal. Here, his 
image of power distribution is evident. There is also an upper class in this universe: they are the ones driving fancy cars and BMWs, Mercedes etc. At the same time, there is a large middle class, where all of the "solid" vehicles and family cars can be found, and then there is the "miserable" lower class, where all of the Ladas and "wrecks" are dominant. The people in the BMWs (i.e. the upper class)- are capable of driving away from the others. As such, the types and brands of automobiles thus reproduce some of society's fundamental class distinctions, also found in societal division of labour and in status classes:

Joergen: I mean, truck drivers down in Germany - that is the lowest a person can sink. And that is why there are some big conflicts with some of those BMWs and Mercedes. They feel that they are the ones who have paid for the road, so they [the truck drivers, ed.] had better not sit there and set the tempo and bother them.

Joergen interprets his "practical wisdom" in his own "theoretical" readings such as inferring freedom, equality, fraternity as concepts related to traffic. I will in the following elaborate on these interpretations as an example of what Giddens labelled the "double hermeneutics." The social researcher studies phenomena which are already constituted as meaningful by laymen and turns in "second order" concepts using the metalanguages invented by social scientists (Giddens 1984). In this case this means trying to promote a different kind of knowledge - the type of practical knowledge that Aristotle called phronesis, which means the practical wisdom that grows out of intimate familiarity with practice in contextualized settings: "The local knowledge - even tacit knowledges, that cannot be taught a priori, grown from the bottom up, emerging out of practice, forgoing the hubris of seeking claims to a decontextualised universal rationality stated in abstract terms of false precision" (Schram 2006:28).

The traffic, in Joergen's construction, reveals testimony regarding inequalities and the natural extension of the class struggle. But there is also "good news" from that front; for one can actually break the (class) society determinism: when you are a truck driver, the CEO might well come speeding along in his Mercedes 600, but if you use your indicator and pull out, he can maintain his right all he wants, Joergen says. In other words, Joergen draws some fundamental societal characteristics from this situation. His conceptions of power thus fit with his own, personal experiences and life situation. Joergen uses traffic as the basis for his description of the world as "every man for himself." It is all about survival, and ultimately we all have to take care of ourselves, he claims. The truck drivers represent the "underdogs" and proletariat on the road. They suffer under poor working conditions; they are the ones hauling the biggest load; they are the ones that are making their way the most slowly in the chaotic traffic; and they are generally unwelcome in the traffic. Under these conditions, they join together in a form of community. As such, the conventional relations can also be turned on their head, and the truck also becomes a concrete symbol of power. For the ultimate force belongs to the truck on the strength of the power derived from its dimensions and raw power - it can flatten all of the other vehicles in the event of a direct confrontation. In a sense, the truck drivers will always ultimately have the power on the road. From time to time, a smouldering class riot does indeed flares up: the truck drivers become rebellious. And they know that they are invincible as long as they unite. They have long ago discovered the advantages to be had in solidarity and collective organization, cf. the "convoy" phenomenon. They are strong individually, but collectively they are untouchable in relation to the others on the road. Occasionally, the long-distance truck drivers gang up against a specific opponent: "Oh yeah. Once we were even four or five guys who got together and locked a guy in, so that he was between the four trucks", says Joergen. In the situation Joergen refers to, the trucks surrounded a German BMW on the highway, two in 
front of it and two behind it:

Joergen: Yeah, we locked him in. I mean - they come along with the pedal to the floor. We can see them from a distance - here comes a guy in a hurry. But on the other hand: we also want to be able to pass once in a while, so we work up a proper head of steam so that we can make a quick and efficient passing. So you are sitting there thinking, "When is it time to go?" and suddenly you say to yourself, "Now!" and you hit your indicator. And then he comes zooming up and he is flashing his high beams and then when he comes up alongside of you, he gives it to you with everything he has got. So then you call out to the guy in front of you, "Try to pull out"! And then you've got him. I can just remember him sitting there, hanging out of the window. He got a chance to cool off a little.

Life on the road can well assume the character of a real "wild west" life. To a certain extent, you make your own rules, and woe is he who dares to challenge the dominant order and its actors:

Joergen: I have also heard about a guy [trucker; my addition NNK], who obviously also pulled out, and then the BMW in question drove in front of him and braked. I have also tried that - you are about to slam into him from behind. So you have to brake, and all of the shit you have in the back gets thrown around. But this guy, he didn't brake - he just kept his foot on the gas and steamrolled over him.

Joergen's example illustrates how power relations can be turned on their head: the CEO is disempowered and must involuntarily subject himself to the force and caprice of the truck drivers, while for Joergen; the situation represents the unavoidable liberation from the determining structures and class distinctions. By no means, however, are the boss-types or the wealthy the only scapegoats in Joergen's traffic-universe. Generally, he simply does not have much good to say about the others on the road: "At one level or the other, it is just as much all the other nitwits out there. When it begins to get a little slippery, there are some people who slow right down. They see ice rinks all over the place. Or else a tractor comes rolling along", Joergen explains. For the ultimate confrontation is when a truck on a relatively narrow road meets a tractor or a different kind of agricultural vehicle:

Joergen: An oncoming combine harvester with everything stretched out over both lanes - I mean, if one of those things comes along, I just stop the truck. Then it is his problem to get around me. If I pull all the way into the side and I have stopped my truck, then if he gets into an accident, it is his responsibility. Those guys have really had some problems getting by. It just can't be right that I have to drive my truck into the ditch.

It appears rather obvious that Joergen protects his autonomy, and that he attaches central parts of his understandings to traffic. But how should we determine the foundations of this identity construction? The role of truck driver in the case of Joergen is not to be understood as an essential identity or a kernel of identity, neither is it as such an "imposed identity", "pressing" Joergen into certain forms of consciousness, that are useful and supportive of his survival and personal development and existence. Rather, I think, it must be seen as an opportunity or as a central "offer" in the labour of identity formation, which modern and reflexive individuals constantly construct in everyday life through different experiences and processes of identity seeking. Different roles are intertwined in the political horizon of reflection through the diverse fields of opportunity and experience that are related to the points of exchange between everyday life and political institutions and political publics. In short, the ways in which we look 
upon and understand political life.

Here, I believe, the bottom up approach shows its relevance: Rules are always constituted locally by the actors themselves, and in context, rather than being law-like phenomena, or an objective instantiation of a general principle or law. Contextualism in this sense implies that empirically occurring regularities are always situational, and not the result of either remote laws operating behind the backs of the actors concerned or an idiosyncratic researcher's interpretation of the scene in question. This notion is very similar to Althusser's (1983) concept of interpellation. To interpellate is to be called for by something and in this process to take upon your own shoulders to identify with a particular idea or identity - and more precisely the process by which you recognize yourself as belonging to a particular identity. The specific construction of the truck driver identity must be seen as the individually experienced, contextual and simultaneous interpretation of both structure and agency. Not just "one side of the coin." Understanding is framed within deeply embedded foundations that the actors find normal and acceptable to use. Rationality, in other words, is therefore always implicated with power: "No context stands outside power. If that were the case, then it would exist nowhere, outside understanding, outside possibility, outside sense" (Clegg, 2006:174).

\section{Conclusions}

In this paper I have presented a framework for a "hermeneutics of the political subject"building on a bottom up methodology and a constructivist ontology. I have argued for a qualitative methodology and the use of approaches that are "interpretive" and involve the attempt to discursively grasp the consciousnesses and senses of meaning that identities involve for the human beings who possess them. What is gained from the use of this approach, which a "standard" design would not capture? The case of Joergen - standing alone - is naturally hardly useable for causal theorising. Still, it seems possible to submit some common patterns in relation to power perceptions, identity and empowerment. Joergen is obviously just one example - a single case - but the findings line up with other respondents in the case study showing a theoretical representativity (Riis, 2001), and they reveal a more general pattern: people often use their practical consciousness to structure perceptions of power, and as a central building block in the political identity formation. The larger case study revealed nuanced perceptions of power. However, people often tend to conceptualise power as being blurred, systemic and structural. Nevertheless, they apparently do not feel powerless or distant from power. Paradoxically, while experiences of power as "system" are common, the actors appear to be both resourceful and active. Confidence in individual capacity to make a difference seems considerable.

Certain basic understandings are maintained in this approach. First, it is explicitly political. This means - at the ontological level - that it understands individuals as guided by political motives, rationalities and interests, which they will defend and act upon. The world is political - and according to our identities, roles and positions, we will defend such interests. This means, e.g. in relation to case studies, that involved actors have certain interests at stake in the case. These are in general merely and fundamentally different, which is acknowledged and taken as a part of departure. It is the task of the researcher to have these interests or versions of "truth" unfolded in order to have the material analysed hermeneutically and to approach a position from where conclusions can be made. The most obvious route to enhancement of research quality is to link the designing of the methodological approach closely to the purpose of the study. The approach favours the case study for its holistic appreciation, emphasising the importance of context: identity and meaning are linked to the understanding of individuals' 
meaningful social practices (Kristensen, 1996). It investigates how power is interpreted through "life world lenses." The participants own narratives are the starting point for the analyses of political identities and the approach pays interest in the meaning, which individuals themselves ascribe to action and behaviour. If you wish to understand what someone is doing - you might probably ask him. He could be lying of course - but you would get access, criteria of distinction and types of categorizations through which he constructs his conscious world. The conversation is the most obvious route into this world. It is guided by the interviewer (Lewis, 1991). Only interpretation is the entrance to this kind of knowledge, as facts do not speak for themselves. A valid qualitative study is one that takes into consideration the context of those who are the subject of inquiry and analyses, how phenomena are made meaningful for people. The identities and the life worlds of the individuals involved can, following, not be uncovered in a "top down" manner. This is exactly the condition which renders the concept of contextuality so crucial.

The approach looks for codes of practice - recognizing the mechanisms of power that might be hidden within these practices - and hereby to some extend emulating Ricoeur's notion of "the hermeneutics of suspicion" (Ricoeur, 1981). This signifies a method of interpretation which assumes that the literal or surface-level meaning of a text is an effort to conceal the political interests which are served by the text (Gripsrud, 2002). It is a critical strategy of interpretation aiming to strip off the concealment, unmasking those interests. It thereby suspects the credibility of the superficial text and explores, what is underneath the surface to reveal a more authentic dimension of meaning (Ricoeur, 1981), like I have tried to demonstrate in the case of Joergen. Respondents are the owners of views, and you have to acknowledge and validate your findings and interpretations. Studies that take interpretations as their frame of reference are only as ontologically secure as these intersubjective interpretations are stable (Clegg, 2006). So, what kind of validity can be attached to the study? In the constructivist methodology the concept of validity is generally not a matter of genuine concern (Hansen, 2003). Clearly, this adds to the problems of this approach: We don't really know. This is, however, after all a basic condition of all scientific methods. In constructivist approaches, the validity of a study is not determined with reference to certain scientific methods or a study's replicability, but on how a given interpretation may be judged: Is it thorough, coherent, comprehensive? Does it make sense, or ring true? Is the interpretation provocative and generative of further inquiry? If a study meets these criteria, it may be said to be valid (Clark, 1999). An anti-essentialist approach distances itself from the classic, objective paradigm of "truth", which regards recognition as a process in which an investigative subject with value-neutral, scientific instruments uncovers a self-supporting object and its riddles. In this sense, recognition is not a "pure", clinical process; to the contrary, it is a constant, dialectical and conflicting relationship, and the validity of an interpretation depends, according to this perspective, on its capacity to convince and acquire status as inter-subjectively plausible within the scientific public (Habermas, 1971; Kaare Nielsen, 1996). I here sanction the Habermarsian notion of communicative validity (Habermas, 1971). The production of knowledge is seen as a social construction of reality (Esmark et al., 2005).

"Assessing qualitative research through a social constructionist lens, however, is premised upon the belief that research findings are always already partial and situated; that they actively construct the social world which is itself an interpretation and in need of interpretation. If we reject the very notion of an empirical world untouched by the social and political, how are we to assess the research claims we make? If we concede that "truth" and "objective knowledge" cannot be invoked unproblematically, upon what grounds are we to say one research claim is 
better (i.e. valid) than another?" (Aguinaldo, 2004:135)

Constructivists often argue that there are many possible interpretations of the same data, all of which are potentially meaningful (Guba \& Lincoln, 1989). How, then, are we to judge an interpretation as being a valid one? Often, if we emphasize meaning at the individual and local level, there is a tendency to downplay power relations that privilege certain constructions over others. Constructivists are therefore often accused of being idealists with little to say about the material world (Clark, 1999). A common critique against constructivist studies points to the risk of relativism - or the matter, that one interpretation might be as good as any other. This is, however, not necessarily the case: explanations and interpretations may well be judged against each other. And not all contributions are equally valid. Constructivism only claims that it is not possible to "step outside" of interpretations as such - and that every assessment is given within the frames of a given discourse. One can not transcend such frames and provide universal evaluations and findings. Constructivism does not reject the notion of truth as such - but rather it internalises this matter within certain discourses (Hansen, 2003). Validity is originally a concept derived from positivism, although it is certainly not exclusively tied to this position. One problem could be, however, that it also serves a discursive function in the social sciences, and the issue of validity can itself be seen as a construction of power: Validity polices the social science enterprise, and thus, to some extent functions as a practice of power through the de/legitimation of social knowledge and research practice (Aguinaldo, 2004). The notion of validity should therefore never be treated as a given concept. On the other hand, we should decline to abandon the concept of validity altogether. Only by questioning the issue of validity and only by presenting plausible and alternative methodological design, we can contemplate scientific dominating positions and expand our knowledge.

Joergen was chosen for analysis in this article because he - in a paradigmatic way, I think exploits political ideas and metaphors in his conceptualizations of everyday life, and notions of e.g. power and democracy are easily found in his verbatim quotes. Also, concepts of autonomy and political empowerment ring out explicitly in his narratives - which make him highly perceptive for analysis. Clearly, Joergen represents a dichotomous understanding of power. And likewise obviously, he tends to conceptualize power through the lenses of his life world using imagery and understandings based on conditions in his near surroundings. This is precisely the reason why the bottom up approach is applicable and that we need to comply with the use of approaches that are "interpretive" and involve the attempt to discursively grasp the consciousnesses and senses of meaning involved for individuals.

We are born equal, and we are equal when we are driving our cars, Joergen says. I argue that the findings in Joergen's case basically are valid. But one should always pay attention when doing studies in the field of political identity formation and transformation, simply because these concepts are very difficult to capture. We need to acknowledge a basic problem and condition related to social research regardless of methodology used: these matters are "hard to handle." The bottom up approach searches for knowledge between the intuitive everyday conceptions and the reflexive views - between the world as it is practically comprehended in an everyday manner - and the same world as it appears in a theoretical reading (Lykkeberg, 2008). Exactly the point where the intuitive everyday conception is retrieved in the theoretical version opens for a different kind of knowledge. The approach endeavours a pluralistic emphasis allowing for more contextual, contingent and multiple political truths that involve a greater tie between theory and practice and a connection between thought and action in specific settings. When analyses open for such identity codes and points of navigation, we should, I believe, gain 
access to fuller insights.

\section{References}

Aguinaldo, J.P. (2004). Rethinking Validity in Qualitative Research from a Social Constructionist Perspective. From "Is this valid Research to "What is Research valid for? The Qualitative Report Vol. 9 No. 1, 127-136.

Althusser, L. (1969). For Marx. Aarhus: Rhodos.

Bang, H. (ed.) (2003). Culture Governance. Manchester University Press: Manchester.

Beck, U. (1992). Risk Society. Towards a New Modernity, London. Sage.

Bennett W.L (1998), "The Uncivic Culture: Communication, Identity and the Rise of Lifestyle Politics", PS: Political Science and Politics, 31, 741-761.

Bennet, W.L. \& Entman, R.M. (2001). Mediated Politics. Cambridge: Cambridge University Press.

Bulmer, M. (ed.) (1975). Working-class Images of Society. Cambridge: Cambridge University Press.

Calhoun, C. (1995). Critical Social Theory. Cambridge: Blackwell Publishers.

Castells, M. (1983). The City and the Grassroots. London. Edward Arnold.

Castells, M. (1996). The Information Age: Economy, Society \& Culture. Vol I-III. Malden: Blackwell Publishers.

Clark, L.S. (1999). Learning From the Field. The Journey From Post-positivist to Constructionist Methods. Paper presented to the International Communication Association, San Francisco.

Clegg, S. (2006). The Bounds of Rationality. In Schram \& Caterino (2006).

Corner, J. \& Pels, D. (2003). Media and the Restyling of Politics. London. Sage Publications.

Dahlgren, P. (2001). The Public Sphere and the Net. Structure, Space and Communication. In Bennet W.L. \& Entman R.M. (2001).

Dahlgren, P. (2003). Reconfiguring Civic Culture in the New Media Milieu. In Corner \& Pels (2003).

Delanty, G. (2000). Modernity and Postmodernity. Knowledge, Power and the Self. London: Sage Publications.

Esmark, A. et al (2005). Poststrukturalistiske analysestrategier. Copenhagen. Roskilde Universitetsforlag.

Flyvbjerg, B. (2001). Making Social Science Matter. Why Social Inquiry Fails and How It Can 
Succeed Again. Cambridge University Press.

Foucault, M.(1982). The Subject and Power. In Dreyfuss \& Rabinow (eds.). Michel Foucault. Beyond Structuralism and Hermeneutics. Brighton: Harvester.

Gibbins, J.R. and Reimer, B. (1999). "The Politics of Postmodernity. An Introduction to Contemporary Politics and Culture, Sage. London.

Giddens, A. (1984). The Constitution of Society. Cambridge: Polity Press.

Giddens, A. (1991). Modernity and Self-Identity, Cambridge: Polity Press.

Gripsrud, J. (2002). Mediekultur, mediesamfunn. Olso. Universitetsforlaget.

Guba, E. \& Lincoln, Y. (1989). Fourth Generation Evaluation. Newbury Park, CA. Sage.

Habermas, J. (1971). Knowledge and Human Interest. Boston. Beacon Press.

Habermas, J. (1996). Between Facts and Norms. Cambridge. MIT Press.

Hansen, A. D. (2003). Diskursteori i et videnskabsteoretisk perspektiv, in Fuglsang \& Bitch Olsen. Videnskabsteori i samfundsvidenskaberne. Roskilde Universtitets Forlag.

Hoff, J. (2003). A Constructionist Bottom-up Approach to Governance. The Need for increased Theoretical and Methodological Awareness in Research, in Bang (ed.) (2003).

Jenkins R. (2004). Social Identity. London: Routeledge.

Kaare Nielsen, H. (1996). Kultur og modernitet, Århus Universitetsforlag.

King, G., Keohane, R. \& Verba, S. (1994). Designing Social Inquiry. Princeton. Princeton Univesity Press.

Kristensen, N.N. (1996). Felt-studier. - Metodiske og videnskabsteoretiske overvejelser forud for gennemførelsen af en konkret caseundersøgelse. Arbejdspapir, Institut for Økonomi, Politik og Forvaltning, Aalborg Universitet, 1996.

Kristensen, N. N. (2003). Billeder af magten - portrætter til forståelse af magt og demokrati. Århus. Århus Universitetsforlag.

Kvale, S. (1994). Interview. Copenhagen. Reitzels forlag

Laitin, D. (2006). The Perestroikan Challenge to Social Science. In Schram S.F. \& Caterino B. (2006).

Lewis, J. (1991). The Ideological Octopus. London. Routeledge.

Lilleker, D.G. (2006). Key Concepts in Political Communication. London. Sage Publications. 
Lockwood, D. (1975 [1966]). Sources of Variation in Working-class Images of Society'. In Bulmer (ed.) (1975).

Lykkeberg, R. (2008): Kampen om sandhederne. Copenhagen: Gyldendal.

Marx, K. \& Engels, F. (1992 [1848]). The Communist Manifesto. Palo Alto, Ca.: Ebrary

Murphey, J. (1980). Getting the Facts. A Fieldwork Guide for Evaluators \& Policy Analysts. Santa Monica: Scott, Foresman and Company.

Mouffe C., (1993). The Return of the Political. London: Verso.

Prasad P. (2005), Crafting Qualitative Research: Working in The Postpositivist Traditions. New york: M.E. Sharpe.

Ragin, C.C: \& Becker, H.S. (eds.) (1992). What is a Case? Exploring Foundations of Social Inquiry. New York: Cambridge University Press.

Ricoeur, P. (1981). History and Truth. Evanston: Northwestern University Press.

Riis, O. (2001). Metoder på tværs. Om forudsætningen for metodologisk metodekombination. Copenhagen. DJOEF Forlag.

Schatzki, T. (2006). Social Science in Society. In Schram S.F. \& Caterino B. (2006). Making Political Science Matter. New York University Press

Schram, S.F. \& Caterino, B. (2006). Making Political Science Matter. New York University Press.

Smith, R.M. (2004). The Politics of Identity and the Tasks of Political Science. In Shapiro et al. Problems and Methods in the Study of Politics. Cambridge University Press.

Sørensen E., (1998). Hvad er bottom-up forskning for noget og hvad skal vi med den? I Bogasson P. \& Sørensen E.: Samfundsforskning bottom-up. Teori og metode. Roskilde Universitetsforlag.

Van Maanen, J. (1988). Tales of the Field: On writing Ethnography. Chicago: University of Chicago Press.

Yin, R. K. (1994). Case Study Research. Design and Methods. London: Sage Publications.

\section{Author}

Niels Nørgaard Kristensen is an associate professor in the Department of Economics, Politics and Public Administration at Aalborg University, Denmark. Email: nnk@epa.aau.dk 